\title{
Dialogue as Moral Paradigm: paths toward intercultural transformation
}

\author{
J. GREGORY KELLER \\ Department of Philosophy, \\ Indiana University-Purdue University Indianapolis, USA
}

\begin{abstract}
The Council of Europe's 2008 White Paper on Intercultural Dialogue: 'living together as equals in dignity' points to the need for shared values upon which intercultural dialogue might rest. In order, however, to overcome the monologic separateness that threatens community, we must educate ourselves to recognize the dialogism of our humanity and to engage in deep encounters with others with a mature skepticism of all dogmatisms, including our own. In order to aid us in reaching the necessary insight, the author calls upon Bakhtin's ideas of the dialogism of every utterance and of the unity and heteroglossia of language, Gadamer's hermeneutical experience that shakes us loose from what we think we know, and Levinas's description of that transcendent ideal of a dialogue beyond reciprocity. These perspectives break open our certainty that tribalism and individualism are fundamental, placing them instead as secondary phenomena that, though powerful, pronounce neither the initial nor the final word on our life together.
\end{abstract}

If there is a European identity to be realised, it will be based on shared fundamental values ... Intercultural dialogue can only thrive if certain preconditions are met. (Council of Europe, 2008, p. 4)

The realization of shared values - the precondition for intercultural dialogue and for living together into a common future - depends upon a previous or concomitant recognition of the dialogism of life.

We see in Bakhtin (1981) the idea of every moment's utterance being caught up in the dialogism of the endless human conversation that makes our lives what they are. Such dialogism is nothing one does specifically; it stands as the background for each and every act of communication, even of silence. Alfred North Whitehead $(1929,1933)$ describes the nature of the fundamental actuality in the universe - what he calls the 'actual occasion' - in terms of its deep and unavoidable place as response to the past and as anticipation of the future. H. Richard Niebuhr (1963) deems human beings as 'answerers' whose life consists of response to our interpretation of life and to which we expect a response in turn. These thinkers cast basic experience as dialogic, whether in relation to the dialogism of the ongoing social conversation or to the nature of the world itself. I seek first to draw out a few of the implications of the life of dialogue, the life of person in community as answerer in the midst of dialogism, as a way to understand and possibly transform the moral life or, I would suggest, simply the life of being human.

We read in Gadamer (1991, p. 369): 'That a historical text is made the object of interpretation means that it puts a question to the interpreter'. Prior to our turning to a particular text or relationship or mode of life - prior, that is, to our making some event, thing, or relationship into an 'object of interpretation' - the conditions and context in which we find ourselves put a question to us, or rather place us in a matrix of questions (or 'problems' [1]) that sets the tone for our later 


\section{J. Gregory Keller}

choices and practices. As Foucault points out, practices of the self (our modes, means, and methods of everyday conduct) indicate ways in which 'the subject constitutes itself in an active fashion' in a way that is 'not something invented by the individual himself. Such practices arise from 'models that ... are proposed, suggested, imposed upon him by his culture, his society, and his social group' (Foucault, 2003b, p. 34).

Yet, the situation signals more than that. Not only are the models we appropriate placed in our hands by our life conditions and context, but all our life practices in terms of choices or actions and attitudes, as well as habits and character, are most clearly apprehended as responses in a dialogic interaction. Bakhtin (1981) opens this metaphor in a particularly helpful way by speaking of the dialogism of language and of each utterance. We are always in the midst of a conversation that we did not begin and that we will not bring to a close, even while our participation and interpretation play a substantial role in creating the dialogue itself. We note that Bakhtin's notion applies not just to language but to life - not only our words, but more significantly our lives are instances of dialogism. Further, Whitehead $(1929,1933)$ places every actual occasion of subjectivity within the context of a creative transition from past to future. Each moment in the life of every subject exists as an interpreted re-enactment of the past that in its turn issues in an orienting anticipation and creation of the future. In both cases we see a natural unfolding of the dialogue (or dialectic) of unity and plurality - we are always already one with our broadest possible society and at the same time distinct from it.[2] Thus, we can never truly know ourselves as wholly separate, nor can we truly recognize in ourselves only the collective reality of the hive.

Armed, then, with this conception of life as dialogic, we ask about the values implied by this idea, especially in terms of intercultural dialogue. First, we must note that a theory of life as dialogic can lead us to ignore the actual experience of an everyday life that frequently seems obsessively bound instead to the monologic. Monologism occurs in at least two obvious ways: individuals see themselves primarily in terms of their separate lives and interests - for example, the 'rational agent' of economic theory whose every action arises solely from the desire to maximize personal gain. Second, the power of the tribal strikes at the heart of any notion of universal rights, 'shared fundamental values', or reasoned dialogue; everyday news as well as theoretical considerations lead us to wonder whether the Enlightenment fantasy of universal rational discourse was ever, and could ever, prevail.

News stories bring to our attention, for example, attacks on Roma families with firebombs and guns, as well as waves of ethnic violence in various parts of the world. We do not need news stories to be reminded frequently of the verbal and physical violence that people are prone to inflict on one another. In the face of such long-term and ongoing evidence of, let us say, monologic divisiveness, how can we offer talk of the dialogic nature of human life as though it amounts to anything other than a comforting illusion? Are we not more essentially monologic than dialogic in our dealings with one another in general, and especially with those who are 'not like us'?

In the concrete situation of the European Union, with its inherent multiplicity, multi-ethnicity, and the various languages, histories, cultures, and so on that go with these pluralities, we find a variety of reasons for focusing on the monologues of difference - and thus potentially tuning out the dialogic - as well as a multitude of reasons for recognizing and engaging in a practice of dialogue. The dialogism of life itself underlies both alternatives. The desire to separate and differentiate and to ignore or even attack the otherness of others arises from the point at which one's (and one's group's) life conversation stands now. The same is true of any desire to interact. Although we can live in a pretense of avoiding dialogue, we cannot carry out the attempt to separate and isolate ourselves and our group, for we are implicitly and fundamentally engaged with the world from the moment of our conception (and even, one could argue, before).[3]

The sources we will appropriate to further our approach to dialogue lie in the work of HansGeorg Gadamer, Martin Buber, and Emmanuel Levinas. Although Buber provides the early ground-breaking view of dialogue in terms of the alternatives of an I-It or an I-Thou approach to the other, and Gadamer offers an interesting understanding of the I-Thou in a hermeneutic relationship, we will find a useful resolution of our concerns in the discussion of dialogue offered by Levinas.

First, let us turn to Gadamer's (1991) description of dialogue and its importance in Truth and Method. In attempting to explain the hermeneutic work that, Gadamer believes, lies at the heart of 
the 'human sciences' (Geisteswissenschaften), he says that '[i]n understanding tradition not only are texts understood, but insights are acquired and truths known' (Gadamer, 1991, p. xxi) and that this process includes 'modes of experience in which a truth is communicated that cannot be verified by the methodological means proper to science' (p. xxii). He says that the resulting 'experience of truth ... is itself a way of doing philosophy' (p. xxiii). We end up in this case not with a technique or method over which we exercise full control, but rather with a developing experience that transforms us because it is of the nature of experience itself.

At the heart of this experiential self-transformation lies dialogue. We discover, Gadamer (1991, p. 355) insists, that the natural movement or 'dialectic of experience has its proper fulfillment not in definitive knowledge but in the openness to experience that is made possible by experience itself. This means, in turn, that experience can be understood most fully by thinking in terms of dialogue, which is known best through the 'logic of question and answer' (p. 369). We then 'approach the mystery of language through the conversation that we ourselves are' (p. 378). Gadamer further says:

To reach an understanding in a dialogue is not merely a matter of putting oneself forward and successfully asserting one's own point of view, but being transformed into a

communion in which we do not remain what we were. (Gadamer, 1991, p. 379)

We may draw from Gadamer the idea that experience itself, as that which negates conclusions reached through prior experience by means of the questions experience itself naturally raises, on the one hand is the model for, and on the other is modeled after, dialogue. And dialogue itself both offers and requires a form of transformation. Based upon this conclusion, we see that personal as well as interpersonal transformation follows a line of movement initiated by experience itself in its dialogic aspect.[4]

Let us take up our transition to Levinas through the following words of his: 'Dialogue is thus not merely a way of speaking ... It is transcendence' (Levinas, 1998a, p. 147). In other words, Levinas seems to agree with Gadamer that dialogue acts as transformative practice. Yet, we find in Levinas an explicit attack on the notion of 'experience' as "received lessons" that converge into a unity of knowledge' (pp. 137-138). It 'entails a grasping ... a hold on what is learned, and a possession' (p. 138; original emphasis). In this way, then, 'Reason would be the true inner life ... It has no one left with whom to communicate; nothing is outside of it' (p. 141) and, consequently, 'the unity of ... multiple consciousnesses ... ha[s] entered into the same thought in which their reciprocal alterity is suppressed' (p. 141; my emphasis) - so that 'experience', here, stands for the unity of knowledge, the hegemony of reason in which no room is left for others or even for oneself.

Levinas moves from this notion of experience or self-consciousness as a unitary and complete form of knowledge to a dialogic sense of oneself encountering another. In this transition, for Levinas, 'experience' is replaced with relation. Experience is seen as an I-It approach to life, in contrast to the I-Thou of relation, drawing on Martin Buber (1996). Turning back to Gadamer (1991) for a moment, we see in Truth and Method that a certain type of experience [5] functions only as a gathering of information, by which one gains power over the world. The problem with this type of experience (Erlebnis), for Gadamer, is that it fails to take into account the deeper notion of experience (Erfahrung) that works to undermine our certainties and leaves us radically open to the unknown and unknowable. We are not claiming here that Gadamer and Levinas are saying the same things throughout. That is not so, and if it were, there would be no point in including both of them in our discussion. Our own questions, however, are not well served by our allowing a surface difference to appear deeper than it is.

Concerning experience, then, we see that Gadamer and Levinas share a common distrust of it when it functions as a hegemonic dispenser of certainties, and value instead the breaking up of any false unity by which reason claims to reign supreme, denying or burying any question that stands in its way. Questions play a primary role, and with them dialogue, a role that cannot be denied without giving way to a false totality that governs every thought and practice from a citadel defended by the false logic of answers that need not answer further to the array of questions that surround them. On the other hand, even if we find some continuity of thinking between Levinas and Gadamer on experience, their notions of the I-Thou relation seem far less compatible.

Gadamer distinguishes three forms of alleged I-Thou relations. First, one listens and meets the other simply for the sake of prediction and control, for the sake of an understanding of human 


\section{J. Gregory Keller}

nature or at least of this particular other so as to remain easily dominant in the relationship. Second, one recognizes the other as a person rather than as an object but meets every word of the other with a counter-word, using the relating as a means of self-assertion or even self-development. In this case, one believes that one knows the other better than he/she knows him- or herself, and thus one is not and cannot be disturbed by the other's words or presence. Third, however, we might meet the other and actually listen, hearing the words and encountering the other in a way that puts one's own ideas into question. Only this latter form of meeting has transformative potential, and indeed it is this form of encounter from which Gadamer (1991) draws his notion of experience as disturbing, as a form of genuine dialogue, as a logic of question and answer [6] that requires and, in fact, is radical openness.

Levinas, however, acknowledges a dialogical encounter similar to the ultimate one in Gadamer's approach then moves beyond it. One might say that in Levinas, as in Buber before him, one can meet the other as object, as subject, and further as that which cannot be named or placed and which therefore functions not only to teach or share but to unravel one's grasp of self and all that one believes one can control or understand. One way that Levinas raises this point is as follows: 'This is not a situation in which one poses the question; it is the question that takes hold of you: there you are brought into question' (Levinas, 1998b, p. 85; second emphasis mine). In the deepest encounter, we are not just learning something new, not just having our knowledge challenged and transformed. Our very being is at stake. It is further the case that " $\mathrm{e}]$ thics begins in the I-You of dialogue' and that '[ $t$ ] here would be an inequality, a dissymmetry, in the Relation' (Levinas, 1998a, p. 150) that opens the individual to something beyond simply an amplification of self or a dogmatic contemplation of the same.[7] Dialogue may be seen in this way as an ultimate movement beginning from the reality of the other and culminating in an inner revolution, a reaching that cannot stop with concerns focused on oneself but must lead to 'a thought thinking beyond the given' in which 'I think more than I can grasp' (Levinas, 1998a, p. 151; original emphasis).

Where does this leave us in our attempt to find the underlying principles that can forge dialogue across difference? We function here in multiple dimensions simultaneously. First, there lies the bare necessity of dialogue as a means to the end of holding back a 'war of all against all', turning aside from the apparent demands of separateness that threaten broader community. Without dialogue, without a conscious attempt to listen and to speak, we devolve into monads crashing disastrously against one another. Dialogue functions here on the most primitive level of civility and mutual advantage. This alone, of course, provides basic safeguards against the equally primitive possibility of random eruptions of violence. 'Let's talk' seems far more advantageous than 'let's fight' when it comes to our proximity to others. This arena opens onto the morality of dialogue as Foucault (2003a) speaks of it in relation especially to 'games of truth' (but also to 'relations of power' and 'practices of the self), in which we must engage if we would expand the horizons of our easy dogmatism. Without engaging one another dialogically, we lose the potential for genuine truth-seeking, by which we learn what we need both for self- and societal preservation and for selfand societal growth.

This acknowledgement alone, however, leaves the heat still rising under the simmering miseries of tribalism and individualism run amok. Only when we begin to recognize our own and our mutual dialogism do we move onto the new and firmer ground of principles that sustain the attitudes and hopes of intercultural dialogue beyond essentially economic decisions concerning whether direct and immediate advantage can be gained. Craftiness can undermine dialogue's potential if we rely exclusively on maintaining a quid pro quo. The politician's or news commentator's pretense of dialogue appears as equal exchange when, in fact, it functions instead as false advertising. Similarly, intercultural dialogue cannot rest on a cleverly executed facade of speaking together undertaken merely for the sake of image and leverage.

The most basic underlying truth of our nature revolves around our dialogic engagement with the world that stirs us to expand ourselves and to care for our neighbors and ourselves. Only the openness of 'experience' (Erfahrung), of transcendence, of the I in deep recognition of a Thou, fulfills that nature. Pretense will not do it. Cleverness fails. The rational economic agent cannot meet the other in that mutual reciprocity that alone completes our dialogism. We are essentially answerers, utterances, actual occasions deeply enmeshed in an ongoing, shifting, unfathomable, 
and uncontrollable conversation that never leaves us alone and that makes us inseparable from our neighbor, even in our most individual moments.

Intercultural dialogue requires recognition of our mutuality, our plurality, and our inescapable engagement with one another in a way that requires flexibility, a deep skepticism of all firmly held beliefs [8], and the reciprocity demanded by the interwoven unity/plurality of human language and society. We may even be required to reach for the transcendence that recognizes the other before oneself - without the other I lose the open space of growth and I lose the fundamental grounding of my humanity.

So what do we say to the firebombers, to all those who would destroy the different? On the one hand, we have nothing to say. It is as Aristotle (Nicomachean Ethics Book X, 9, 1179b, 1-10) claims: those who do not love the beautiful cannot be moved by mere argument; or as Hume (1998, p. 155) suggests: to someone who refuses the 'obvious' benefits of virtue over vice, we, in the end, can raise no fully motivating argument.[9] To both these thinkers, virtue seems obviously better than vice, but they both equally acknowledge that one can maintain the opposite and still exist in a truncated form of human society. Dialogism is our natural environment from which we cannot escape. That does not imply, however, that we will live a consciously dialogic life. Just as we are able to ignore simple rules of health and simple rules of clear thinking, so too we can ignore simple rules of human community. But there is always a cost. Unfortunately, in each of these cases, the entire community bears the weight of our ignorance, whether it be willful or not.

We, then, are called upon to provide an education for dialogue, and such an education can be seen as Socratic and, let us say, Levinasian. On the one hand, we must open a path toward Socratic citizenship (Villa, 2001), educating ourselves and one another toward a pliable skepticism of the absolutes bandied about by far too many alleged authorities - a sort of mass vaccination program, if you will, against that dogmatism by which one's own tribe or even one's own self becomes the sole bearer of humanity and truth. On the other hand, and of equal importance, we must find the means not only to seek truth and avoid falsehood together, but also to meet one another as authentically as we can, to discover that level of I-Thou relationship by which we not only find the transformative possibilities of true experience, but even transcend that level of meeting toward a level of contact that shows us the face of our common unity and plurality so that in our encounter with the other we meet both ourselves and otherness itself.

Our lives are always already dialogic. We are inevitably caught up in a web of connection and mutual concern. Blindness to our state remains both possible and, in some ways, highly probable. But we can seek to avoid becoming blind leaders of the blind; we can at least in some meager ways climb out of the cave of individual, ethnic, and tribal certainties and meet there the hope for a dialogue between persons and cultures, if not in the full light of day, then at least no longer mired in the shadowy world of monologic self-aggrandizement and violence.

\section{Notes}

[1] On problematizations, see Foucault (2003a). On Bergson's problematizing approach, see also, for example, Deleuze (1990).

[2] One way Bakhtin (1981) describes this is in terms of the unity of language and the heteroglossia of its use.

[3] We do not mean to engage in a false positivism, such as the one Adorno (1973) and Gadamer (1991) accuse Hegel of engaging in; we are merely trying to clarify the starting point for any discussion of the possibilities of dialogue. We begin already immersed in dialogue, but social forces, as well as the big three elements of experience according to Foucault - games of truth, relations of power, and practices of the self - render our dialogism frequently both problematic and invisible to us.

[4] We might here address again the dialogism of Bakhtin (1981).

[5] Erlebnis as differentiated from Erfahrung. With regard to Erfahrung, it would take us too far afield, but would be interesting to discuss the relation between Hegel's (1977, p. 55) brief discussion of experience in the introduction to the Phenomenology of Spirit, Buber's (1996) view in I and Thou (for example, pp. 55-56), and Gadamer's (1991) in Truth and Method (throughout, but especially pp. 358-362). 


\section{J. Gregory Keller}

[6] Gadamer's (1991, p. 370) discussion of the logic of question and answer is developed on the basis of an idea found in R.G. Collingwood.

[7] Levinas famously sees the ethical relation not as a form of reciprocity or symmetry, but as putting the other above oneself, or rather discovering that the other is above oneself in the true order of things (see, for example, Levinas, 1969).

[8] See Villa (2001) for a very interesting argument for a basic Socratic skepticism.

[9] Hume (1998, p. 156) implies, however, that the development of our character, which is of such intimate concern to each of us, belies the belief that we can ignore virtue in the aim to fulfill immediate desires.

\section{References}

Adorno, T. (1973) Negative Dialectics, trans. E.B. Ashton. New York: Seabury.

Bakhtin, M.M. (1981) Discourse in the Novel, in C. Emerson \& M. Holquist (Trans.) The Dialogic Imagination: four essays. Austin: University of Texas Press.

Buber, M. (1996) I and Thou, trans. W. Kaufman. New York: Touchstone.

Council of Europe (2008) White Paper on Intercultural Dialogue: 'living together as equals in dignity'. Strasbourg: Council of Europe.

http:/ / www.coe.int/t/dg4/intercultural/source/white\%20paper_final_revised_en.pdf

Deleuze, G. (1990) Bergsonism, trans. H. Tomlinson \& B. Habberjam. New York: Zone Books.

Foucault, M. (2003a) Polemics, Politics, and Problematizations: an interview with Michel Foucault, in P. Rabinow \& N. Rose (Eds) The Essential Foucault. New York: New Press.

Foucault, M. (2003b) The Ethics of the Concern of the Self as a Practice of Freedom, in P. Rabinow $\&$ N. Rose (Eds) The Essential Foucault. New York: New Press.

Gadamer, H.G. (1991) Truth and Method, 2nd edn, trans. J. Weinsheimer \& D.G. Marshall. New York: Crossroad.

Hegel, G.W.F. (1977) Phenomenology of Spirit, trans. A.V. Miller. Oxford: Oxford University Press.

Hume, D. (1998) An Enquiry Concerning the Principles of Morals. Oxford: Oxford University Press.

Levinas, E. (1969) Totality and Infinity: an essay on exteriority, trans. A. Lingis. Pittsburgh: Duquesne University Press.

Levinas, E. (1998a) Dialogue: self-consciousness and the proximity of the neighbor, in B. Bergo (Trans.) Of God Who Comes to Mind. Stanford: Stanford University Press.

Levinas, E. (1998b) Questions and Answers, in B. Bergo (Trans.) Of God Who Comes to Mind. Stanford: Stanford University Press.

Niebuhr, H.R. (1963) The Responsible Self: an essay in Christian moral philosophy. New York: Harper \& Row.

Villa, D. (2001) Socratic Citizenship. Princeton: Princeton University Press.

Whitehead, A.N. (1929) Process and Reality. New York: Macmillan.

Whitehead, A.N. (1933) Adventures of Ideas. New York: New American.

J. GREGORY KELLER is a Senior Lecturer in the Department of Philosophy at Indiana UniversityPurdue University Indianapolis, Indiana, USA, and a Research Fellow at the Center for the Study of Religion and American Culture. His research interests include dialogue as life practice, the philosophy of literature, cosmopolitanism, the philosophy of religion, and the relationship between morality and thought. His articles have appeared in such journals as Philosophy and Literature, ProtoSociology and Sophia. Correspondence: J. Gregory Keller, Department of Philosophy, Indiana University-Purdue University Indianapolis, 425 University Boulevard, CA 344C, Indianapolis, IN 46202, USA (jgkeller@iupui.edu). 